\title{
Group II intron-mediated deletion of lactate dehydrogenase gene in an isolated 1,3-propanediol producer Hafnia alvei AD27
}

\author{
Ewelina Celińska ${ }^{\bowtie}$, Agnieszka Drożdżyńska, Agnieszka Wita, Wojciech Juzwa, Wojciech \\ Białas, Katarzyna Czaczyk and Włodzimierz Grajek
}

Department of Biotechnology and Food Microbiology, Poznan University of Life Sciences, Poznań, Poland

\begin{abstract}
Our previous studies showed that glycerol fermentation by Hafnia alvei AD27 strain was accompanied by formation of high quantities of lactate. The ultimate aim of this work was the elimination of excessive lactate production in the 1,3-propanediol producer cultures. Group II intron-mediated deletion of Idh (lactate dehydrogenase) gene in an environmental isolate of $H$. alvei AD27 strain was conducted. The effect of the $\Delta \mathrm{ldh}$ genotype in $H$. alvei AD27 strain varied depending on the culture medium applied. Under lower initial glycerol concentration (20 $\left.\mathrm{gL}^{-1}\right)$, lactate and 1,3-propanediol production was fully abolished, and the main carbon flux was directed to ethanol synthesis. On the other hand, at higher initial glycerol concentrations (40 $\left.\mathrm{gL}^{-1}\right)$, 1,3-propanediol and lactate production was recovered in the recombinant strain. The final titers of 1,3-propanediol and ethanol were similar for the recombinant and the WT strains, while the $\Delta$ ldh genotype displayed significantly decreased lactate titer. The by-products profile was altered upon Idh gene deletion, while glycerol utilization and biomass accumulation remained unaltered. As indicated by flow-cytometry analyses, the internal $\mathrm{pH}$ was not different for the WT and the recombinant $\Delta$ ldh strains over the culture duration, however, the WT strain was characterized by higher redox potential.
\end{abstract}

Key words: 1,3-propanediol, gene knock-out, metabolic engineering, Enterobacteriaceae, group II intron, lactate dehydrogenase

Received: 19 May, 2016; revised: 01 July, 2016; accepted: 14 November, 2016; available on-line: 03 March, 2016

$\triangle$ e-mail: celinska@up.poznan.pl

Abbreviations: AcA, acetic acid; AA, amino acid; $\mathrm{EtOH}$, ethanol; FA formic acid; $H$. alvei AD27, Hafnia alvei AD27; K. pneumoniae, Klebsiella pneumoniae; K. oxytoca, Klebsiella oxytoca; LA, lactic acid; LDH, lactate dehydrogenase OD, optical density 1,3-PD, 1,3-propanediol 1,3-PD dh, 1,3-propanediol dehydrogenase; SUC, succinic acid; WT, wild type

\section{INTRODUCTION}

1,3-propanediol (1,3-PD) is a widely recognized building-block chemical with a number of industrial applications, e.g., in production of cosmetics, lubricants, drugs, and synthetic polymers (Sabra et al., 2015; Saxena et al., 2009; Zeng \& Sabra, 2011; Zeng \& Biebl, 2002). It can be produced through either chemical synthesis or in biotechnological processes by microorganisms belonging to several phylogenetic groups. The major players in microbial 1,3-PD production are representatives of Enterobacteriaceae and Clostridium species. Both groups are characterized by specific traits, making them desired in a specific bioprocess set up. From Enterobacteriaceae family, Klebsiella pneumoniae and $K$. oxytoca are the most widely explored and exploited species in biotechnological 1,3-PD production, due to many advantageous traits (for review see Celińska et al., 2012). However, Klebsiella spp belong to a second hazard group which limits their application in biotechnological processes. Some other representatives of Enterobacteriaceae were also reported to produce 1,3-PD at considerable amounts, like Citrobacter freundii (Homann et al., 1990; Metsoviti et al., 2013), Enterobacter agglomerans (Barbirato et al., 1995), Shimwellia blattae (Rodriguez et al., 2016) and recently also Hafnia alvei (Drożdżyńska et al., 2014). The latter species stayed within the focus of this study.

1,3-PD is synthesized during glycerol fermentation. The topology of the glycerol dissimilation pathway in Enterobacteriaceae is commonly known, and was scrutinized in many studies and described in details in a number of papers (Fig. 1) (Ahrens et al., 1998; Lin, 1976; Zhang et al., 2008). Briefly, 1,3-PD is an end product of the reductive branch of the glycerol dissimilation pathway. The oxidative branch leads to the formation of an array of other metabolites, and importantly, it covers reactions that recycle reducing equivalents $(\mathrm{NADH})$ required for 1,3-PD synthesis. Both, the genetic background of the microbial cell and the culturing conditions jointly contribute to the profile of the oxidative branch metabolites. From the 1,3-PD production process perspective, formation of by-products is unfavorable not only due to carbon loss from the targeted metabolite pathway, but also due to toxicity of the chemical compounds to the producer cells. On the other hand, as proved in many scientific reports, the wide variety of side-products formed during glycerol fermentation is advantageous for fine-tuning of the intracellular redox balance and overall cell homeostasis, and full abolition of the oxidative branch metabolites production was accompanied by severe growth impairment (for review see Celińska, 2010).

Due to a great world-wide interest in development of an efficient 1,3-PD production process via biotechnological methods, a number of strategies have been followed towards this end. Apart from intensive bioengineering strategies (Dietz \& Zeng, 2014; Kaeding et al., 2015; Kaur et al., 2013; Metsoviti et al., 2013), metabolic engineering approaches made significant contribution to this field. In fact, the commercialized 1,3-PD microbial production process relies on a genetically engineered E. coli strain (Nakamura \& Whited, 2003). The wide array of genetic engineering strategies reported to date, aiming at 1,3-PD production improvement, can be divided into several major streams: 1) improvement of native 1,3-PD producers by homologous or heterologous over- 


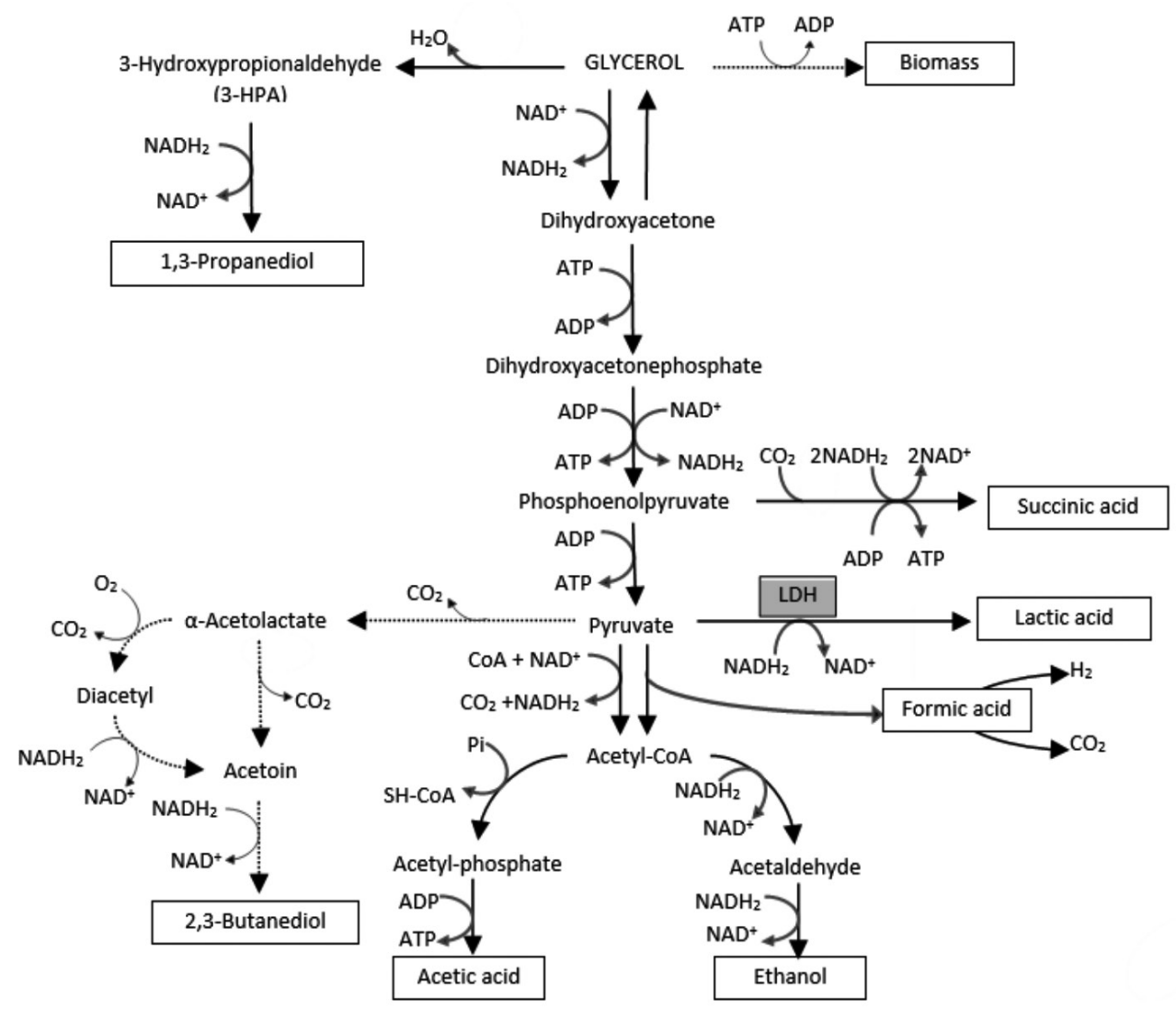

Figure 1. Topology of the glycerol dissimilation pathway in Enterobacteriaceae (modified, based on Drożdżyńska et al., 2014).

The main metabolites are indicated. Dashed lines indicate pathway leading to 2,3-BD formation - neither acetoin nor 2,3-BD was identified in $H$. alvei AD27. LDH - lactate dehydrogenase.

expression of genes directly involved in 1,3-PD production (e.g. Celińska et al., 2015b; Kumar et al., 2012; Wu et al., 2013; Zheng et al., 2006); 2) endowing a strain that is unable to produce 1,3-PD in its native state, with such ability, by expressing genes involved in 1,3-PD formation from the other species (Chen et al., 2015; Hong et al., 2011; Liang et al., 2011; Ma et al., 2013; Rao et al., 2008); 3) elimination of competing pathways involved in by-products formation (discussed hereafter); 4) complex approaches, covering several individual strategies (Kumar et al., 2013; Oh et al., 2013) (reviewed in Celińska et al., 2010 and 2015a). Elimination of competing pathways appears as one of the most promising strategy. According to the results of metabolic flux analysis performed by the group of AP Zeng (Zhang et al., 2008) in K. pneumoniae steady-state cultures, an improvement in 1,3-PD formation cannot indeed rely on a simple overexpression of the reductive branch genes. It was indicated that modifications in direct proximity of pyruvate or acetyl-CoA branch points may affect fluxes distribution, leading to enhancement of carbon flux towards 1,3-PD (compare Fig. 1). With respect to 1,3-PD synthesis, elimination of "unproductive" pathways, has been so far completed in K. pneumoniae and K. oxytoca (Cui et al., 2014; Guo et al., 2013; Horng et al., 2010; Seo et al., 2009; Xu et al., 2009; Yang et al., 2007; Zhang et al., 2006), and recently in Citrobacter werkmanii (Maervoet et al., 2014). The profile of generated metabolites highly depends on both intrinsic properties of the strain and the culture conditions. Amongst the major metabolites produced by Enterobacteriaceae species during glycerol fermentation, one can identify 1,3-PD, 2,3-butanediol, ethanol, as well as organic acids like lactic, succinic, formic and acetic acids (Fig. 1). In majority of the studies on 1,3-PD production by Enterobacteriaceae reported to date, lactate synthesis was not identified as an important factor hampering the diol formation. However, in some specific examples of $K$. oxytoca strains, lactate accumulation reached a level of $40 \mathrm{gL}^{-1}$ (Yang et al., 2007). Although lactate does not exert a heavily toxic effect on the cells, as for example acetate does (Cheng et al., 2005), it was indicated as the primary metabolite to be eliminated in the course of 1,3PD production enhancement (Ahrens et al., 1998; Biebl et al., 1998; Xu et al., 2009; Zeng et al., 1993). Apart from competing for carbon skeletons, thus limiting the yield of 1,3-PD from glycerol, lactate dehydrogenase ( $L D H$ ) is known to compete for reducing equivalents with 1,3PD dehydrogenase (1,3-PD dh). As indicated by Cui et al. (2014), high lactate production restrains sufficient pool of reducing equivalents, available for 1,3-PD $\mathrm{dh}$, imposing constraints on both cellular growth and 1,3-PD formation. Our previous study demonstrated that lactate was the major by-product formed during glycerol fermentation in $H$. alvei AD27 cultures (Drożdżyńska et al., 2014). At higher glycerol concentrations (up to $50 \mathrm{gL}^{-1}$ ) accumulation of lactate was even higher than of 1,3-PD. This observation was the major rationale behind the present study.

The aim of this study was limitation of lactate formation in $H$. alvei AD27 strain. To this end we applied an algorithm-designed retrohomed group II intron for targeted, site-specific disruption of lactate dehydrogenase gene, $l d h$, in this strain. The obtained recombinants were screened for lactate production and further subjected to 
cultivation tests in pre-optimized medium (Drożdżyńska et al., 2014). Additional insight into the molecular background of the observed modification was provided by flow-cytometry analyses.

\section{MATERIALS AND METHODS}

Strains, media and culture conditions. All the strains used in this study are listed in (Table 1). H. alvei AD27 is an environmental isolate, originating from pickled vegetables. Isolation protocol, identification procedures, biochemical characteristics of the strain were all described in (Drożdżyńska et al., 2014). The strain was routinely maintained on nutrient agar slants with $20 \mathrm{gL}^{-1}$ of glucose, at $30^{\circ} \mathrm{C}$. E. coli JM109 and BL21 strains were handled according to standard molecular biology protocols (Sambrook et al., 1989). Routine cultivation was carried out in LB medium (gL-1: yeast extract, 5, bactopeptone, $10, \mathrm{NaCl}, 10$, (agar, 15$)$ ), at $37^{\circ} \mathrm{C}$. When required, LB medium was supplemented with glucose, or appropriate antibiotic (described below).

Molecular biology protocols. Standard molecular biology protocols were used throughout this study (Sambrook et al., 1989). The ldh sequence (1146nt) targeted for disruption is available in GenBank under accession number CP009706.1 (1350409 to 1351555, in antisense orientation). The sequence was found to be highly similar $(98 \%$; blastn, NCBI) to the corresponding sequences from Raoultella, Klebsiella, or Citrobacter spp at the nucle- otide sequence level. The sequence was PCR-amplified from genomic DNA template, using $L D H \_F$ and $L D$ H_R primers pair (Table 1), and RUN TaqDNA polymerase (A\&A Biotechnology). The reaction was set up according to the polymerase provider's protocol, in a VeritiThermalCycler (Applied Biosystems), using the following temperature profile: $94^{\circ} \mathrm{C}$ for $5 \mathrm{~min},\left(94^{\circ} \mathrm{C}\right.$ for $30 \mathrm{~s}, 62^{\circ} \mathrm{C}$ for $60 \mathrm{~s}, 72^{\circ} \mathrm{C}$ for $\left.90 \mathrm{~s}\right) \times 25,72^{\circ} \mathrm{C}$ for $5 \mathrm{~min}$. Amplification products were then separated in 1\% agarose gel. The band corresponding to $\sim 1.1 \mathrm{~kb}$, was excised and purified using Gel-Out kit (A\&A Biotechnology). The purified amplicon was then cloned in pGEMT-Easy vector. The reaction was set-up according to the vector manufacturer's protocol (Promega). Ligation mixture was transformed into E. coli JM109 competent cells (chemical competence, induced by calcium ions) (Sambrook et al., 1989). Plasmid pGEM-T-Easy-ldh was isolated from E. coli positive clones (Plasmid Mini kit; A\&A Biotechnology) and subjected to sequencing (Genomed, Poland). Based on the obtained nucleotide sequence of the $l d h$ gene - IBS, EBS1d, EBS2 (both A and $B$ sets) primers were designed using TargeTron ${ }^{\circledR}$ Design Application (Table 1). Primers were diluted to the required concentration (either 100 or $20 \mu \mathrm{M}$ ) and PCR reaction was set up according to the protocol provided by the manufacturer of TargeTron ${ }^{\circledR}$ system, at the following temperature profile: $94^{\circ} \mathrm{C}$ for $30 \mathrm{~s},\left(94^{\circ} \mathrm{C}\right.$ for $15 \mathrm{~s}, 55^{\circ} \mathrm{C}$ for $30 \mathrm{~s}, 72^{\circ} \mathrm{C}$ for $\left.30 \mathrm{~s}\right) \times 30,72^{\circ} \mathrm{C}$ for $2 \mathrm{~min}$. The obtained amplicons were then separated in $4 \%$ aga-

Table 1. Strains and DNA elements used in this study, with relevant characteristics

\begin{tabular}{|c|c|c|}
\hline Item & Relevant characteristics / Use & Reference / Use \\
\hline \multicolumn{3}{|l|}{ Strains } \\
\hline Hafnia alvei AD27 & wild type strain, isolated from pickled vegetables & $\begin{array}{l}\text { characterized in (Drożdżyńska et al., } \\
\text { 2014) }\end{array}$ \\
\hline E. coli JM109 & $\begin{array}{l}\text { endA1 glnV44 thi-1 relA1 gyrA96 recA1 } \mathrm{mcrB}+\Delta\left(\text { lac-proAB) e14- }\left[\mathrm{F}^{\prime}\right.\right. \\
\text { traD } 36 \text { proAB+ lacla lacZ } \Delta M 15] \text { hsdR17(rK-mK+) } \\
\text { vectors amplification }\end{array}$ & Sigma Aldrich (USA) \\
\hline E. coli BL21 & 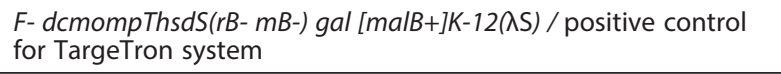 & New England Biolabs (USA) \\
\hline \multicolumn{3}{|l|}{ Vectors } \\
\hline pACD4K-C & the $I d h A$ targeting sequence carrier & $\begin{array}{l}\text { Provided with TargeTron }{ }^{\oplus} \text { Gene } \\
\text { Knockout System }\end{array}$ \\
\hline pAR1219 & T7 polymerase expression & $\begin{array}{l}\text { Provided with TargeTron }{ }^{\circledR} \text { Gene } \\
\text { Knockout System }\end{array}$ \\
\hline pGEM-T-Easy & subcloning of IdhA gene, sequencing & Promega Co. USA \\
\hline \multicolumn{3}{|l|}{ Oligonucleotides } \\
\hline LDH_F & ATGATTATTTCAGCTGCAACCG & \multirow{2}{*}{$\begin{array}{l}\text { IdhA gene sequence amplification from } \\
\text { H. alvei genomic DNA }\end{array}$} \\
\hline LDH_R & TTAGCTCAATCCTTCCTGTACC & \\
\hline IBS_A & $\begin{array}{l}\text { AAAAAAGCTTATAATTATCCTTAATGGTCATCAAAGTGCGCCCAGA- } \\
\text { TAGGGTG }\end{array}$ & \multirow{3}{*}{$\begin{array}{l}\text { Primers for retargeting the LI.LtrB intron } \\
\text { - set A } \\
\text { Designed with TargeTron }{ }^{\oplus} \text { Design Web } \\
\text { site } \\
\text { score: } 7.29 \text { / e-value: } 0.186\end{array}$} \\
\hline EBS1d_A & $\begin{array}{l}\text { CAGATTGTACAAATGTGGTGATAACAGATAAGTCATCAAAGGTA- } \\
\text { ACTTACCTTTCTTTGT }\end{array}$ & \\
\hline EBS2_A & $\begin{array}{l}\text { TGAACGCAAGTTCTAATTTCGATTACCATTCGATAGAGGAAAGT- } \\
\text { GTCT }\end{array}$ & \\
\hline IBS_B & $\begin{array}{l}\text { AAAAAAGCTTATAATTATCCTTACGAGTCGATCCGGTGCGCCCAGA- } \\
\text { TAGGGTG }\end{array}$ & \multirow{3}{*}{$\begin{array}{l}\text { Primers for retargeting the LI.LtrB intron } \\
\text { - set B } \\
\text { Designed with TargeTron }{ }^{\circledR} \text { Design Web } \\
\text { site } \\
\text { score: } 7.06 \text { / e-value: } 0.219\end{array}$} \\
\hline EBS1d_B & $\begin{array}{l}\text { CAGATTGTACAAATGTGGTGATAACAGATAAGTCGATCCGCGTA- } \\
\text { ACTIACCTICTTGT }\end{array}$ & \\
\hline EBS2_B & $\begin{array}{l}\text { TGAACGCAAGTTCTAATTCGGTTACTCGTCGATAGAGGAAAGT- } \\
\text { GTCT }\end{array}$ & \\
\hline EBS_universal & CGAAATTAGAAACTTGCGTTCAGTAAAC & $\begin{array}{l}\text { Provided with TargeTron }{ }^{\circledast} \text { Gene } \\
\text { Knockout System }\end{array}$ \\
\hline
\end{tabular}


rose gel, and the predominant band corresponding to approximately 350 nt was excised from the gel and purified (Gel-Out kit; A\&A Biotechnology). The purified DNA fragment (the re-targeting sequence) was digested with HindIII/BsrGI endonucleases, purified (Clean-Up kit, A\&A Biotechnology) and ligated with linearized pAC$\mathrm{D} 4 \mathrm{~K}-\mathrm{C}$ vector using T4 DNA ligase (NEB); the reactions were set up according to recommendations of the endonucleases and ligase providers. The ligation mixture was then transformed into E. coli JM109 competent cells, further selected for chloramphenicol resistance $(25 \mu \mathrm{g} /$ $\mathrm{mL})$. Selected clones were screened through colony PCR for presence of $350 \mathrm{nt}$ re-targeting fragment. Positive clones were used for the pACD4K-C-ldh_targeting_seq vector propagation and isolation. The same protocol was followed for amplification of pAR1219 vector.

$H$. alvei $\mathrm{AD} 27$ electrocompetent cells preparation and electrotransformation were conducted according to standard protocols, dedicated for E. coli strains (Sambrook et al., 1989). Transformation was set up in Gene PulserXcell $^{\mathrm{TM}}$ Electroporation System (BIO-RAD). Briefly, the competent cells aliquot $(50 \mu \mathrm{L})$ was thawed on ice, both plasmids pACD4K-C-ldh_targeting_seq and pAR1219 were added into the cells at approximately $10 \mathrm{ng} ; 15 \mathrm{~min}$ incubation on ice was followed by electroporation $(2.5 \mathrm{kV}$, $200 \Omega, 25 \mu \mathrm{F}, 2 \mathrm{~mm}$ cuvette) and regeneration in SOC medium at $37^{\circ} \mathrm{C}$ for $1 \mathrm{~h}$, with gentle shaking (100 rpm). The cells were then transferred into LB medium, supplemented with chloramphenicol $(25 \mu \mathrm{g} / \mathrm{mL})$ and ampicillin $(50 \mu \mathrm{g} / \mathrm{mL})$ and incubated over-night at $37^{\circ} \mathrm{C}$ with shaking $(150 \mathrm{rpm})$. In the morning, $40 \mu \mathrm{L}$ of the culture were transferred into $2 \mathrm{~mL}$ of $\mathrm{LB}+$ chloramphenicol $+1 \%$ glucose medium and grown up to OD600 of approximately 0.3 . The incubator was then cooled down to $30^{\circ} \mathrm{C}$ and IPTG was added to the final concentration of $0.5 \mathrm{mM}$. The culture was continued for $30 \mathrm{~min}$, afterwards, the cells were spun down, and regenerated for $1 \mathrm{~h}$ in $\mathrm{LB}+1 \%$ glucose. Finally, the cells were plated on LB agar plates, supplemented with kanamycin at $25 \mu \mathrm{g} / \mathrm{mL}$ (or alternatively $40 \mu \mathrm{g} / \mathrm{mL}$ ). The colonies growing on the LB+kanamycin plates were subjected to cultivation tests.

Batch cultivations. Batch cultivations of $H$. alvei AD27 wild type and the derivative recombinant strains were all carried out in glass test tubes, containing $10 \mathrm{~mL}$ of B20/40 medium, (gL-1: glycerol, 20 or 40, $\left(\mathrm{NH}_{4}\right)_{2} \mathrm{SO}_{4}$, 2, $\mathrm{MgSO}_{4} \times 7 \mathrm{H}_{2} \mathrm{O}, 0.4, \mathrm{CaCl}_{2} \times 2 \mathrm{H}_{2} \mathrm{O}, 0.1, \mathrm{CoCl}_{2} \times 6 \mathrm{H}_{2} \mathrm{O}$, 0.004 , yeast extract, 2, bactopeptone, 2.5, meat peptone, $1.5, \mathrm{~K}_{2} \mathrm{HPO}_{4}, 24, \mathrm{KH}_{2} \mathrm{PO}_{4}$, 6). High phosphate load was necessary for stable $\mathrm{pH}$ maintenance (as demonstrated in Drożdżyńska et al., 2014). Inoculation was done at $10 \%$ with $24 \mathrm{~h}$ culture of the strains, growing on nutrient broth. Cultivations were continued for $72 \mathrm{~h}$, at $30^{\circ} \mathrm{C}$, under static conditions. Time point samples were collected at $0,24,48$, and $72 \mathrm{~h}$, and stored at $-20^{\circ} \mathrm{C}$ until analyzed (except for flow-cytometry analyses, which were conducted immediately). Medium supernatants were analyzed through HPLC for the substrate utilization and metabolites production. Biomass buildup was measured by optical density at $600 \mathrm{~nm}$ using Specord double-beam spectrophotometer (AnalytikJena). All the cultivations were conducted in three biological replicates and all the analyses were done in three technical replicates.

Flow cytometry - FACS analysis. Upon sample collection at the respective time-points of batch production cultures, the cells were subjected to flow cytometry analysis. Two fluorescent dyes were used: BacLight ${ }^{\mathrm{TM}}$ Redox Sensor Green ${ }^{\mathrm{TM}}$ Vitality Kit (Thermo Fisher Scientific) to measure intracellular redox potential of the cells, and $\mathrm{SNARF}^{\circledR} \mathrm{pH}$ Indicator- SNARF-1 (Life Technologies), to estimate intracellular $\mathrm{pH}$. First, the cells were gently deposited by centrifugation (3000 rpm, $3 \mathrm{~min}$; Eppendorf MiniSpin centrifuge). The cellular deposit was then resuspended in sterile 1\% PBS buffer and stained. Staining with the respective dye was conducted according to the manufacturers' protocols. Subsequently, the stained cells were subjected to flow cytometry analysis. Samples were

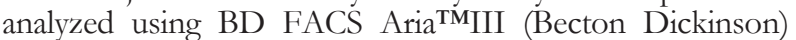
flow cytometer (cell sorter), equipped with 4 lasers (375 $\mathrm{nm}, 405 \mathrm{~nm}, 488 \mathrm{~nm}$ and $633 \mathrm{~nm}), 11$ fluorescence detectors, forward scatter (FSC) and side scatter (SSC) detectors. The instrument setup (optical alignment), stability and performance test was performed using CST system (Cytometer Setup and Tracking) from Becton Dickinson company. FACS Flow solution (Becton Dickinson) was used as sheath fluid. The configuration of flow cytometer was as follows: $70 \mu \mathrm{m}$ nozzle and 70 psi sheath fluid pressure. Cells were characterized by two non-fluorescent parameters: forward scatter (FSC) and side scatter (SSC), and green fluorescence (FITC detector) from RedoxSensor $^{\mathrm{TM}}$ Green reagent collected using 530/30 bandpass filter. For intracellular $\mathrm{pH}$ measurement the following two fluorescence detectors were employed: yellow fluorescence (PE detector) collected using 585/42 bandpass filter and orange fluorescence (PE-Texas Red detector) collected using 616/23 bandpass filter. For excitation of fluorescent reagents, $488 \mathrm{~nm}$ blue laser was employed. The flow cytometry analyses were performed using logarithmic gains and specific detectors settings. The thresholds were set on the FSC signal for intracellular $\mathrm{pH}$ evaluation, and the combination of FSC and FITC (green fluorescence) signals for redox potential evaluation experiments. Data were acquired in a four-decade logarithmic scale as area signals (FSC-A, SSC-A, FITC-A and PE-A, PE-Texas Red-A) and analyzed with FACS DIVA software (Becton Dickinson). Assessment of cellular redox potential was based on median values of green fluorescence (FITC) signals of gated sub-populations defined on bivariate dot plot (FITC vs. SSC). Estimation of intracellular $\mathrm{pH}$ was based on the median values of yellow and orange (PE, PE-Texas Red) signals; precisely on the ratio between the signal intensity from PE and PE-Texas Red dye, according to the manufacturer's recommendations. All the cytometry analyses were conducted for each of the three independent cultures, in technical triplicate.

Analytical procedures - High performance liquid chromatography. HPLC analysis was carried out as described elsewhere (Celińska \& Grajek., 2013). Briefly, the samples were clarified through centrifugation and filtration $(0.45 \mu \mathrm{m}$ membrane syringe filters (Millipore)). The analysis was carried out using Agilent Technologies chromatograph (1200 series), equipped with a refractive-index detector (G1362A) and a Rezex ROA-Organic Acid H+ column (Phenomenex). Operating conditions were as follows: eluent $\left(0.005 \mathrm{~N} \mathrm{H}_{2} \mathrm{SO}_{4}\right)$, flow rate of $0.6 \mathrm{~mL} / \mathrm{min}$, column temperature of $40^{\circ} \mathrm{C}$. Chemicals used as external standards (glycerol, 1,3-PD, AcA, LA, EtOH, SUC, FA, and 2,3-BD) were purchased from Sigma Aldrich (USA). ChemStation LC3D system (Agilent) was used to analyze the chromatographic data.

\section{RESULTS}

\section{Deletion of Idh gene in H. alvei AD27 strain}

Construction of pACD4K-C-ldh_targeting_seq vector was conducted according to standard molecular biology procedures. Determination of the re-targeting sequence 

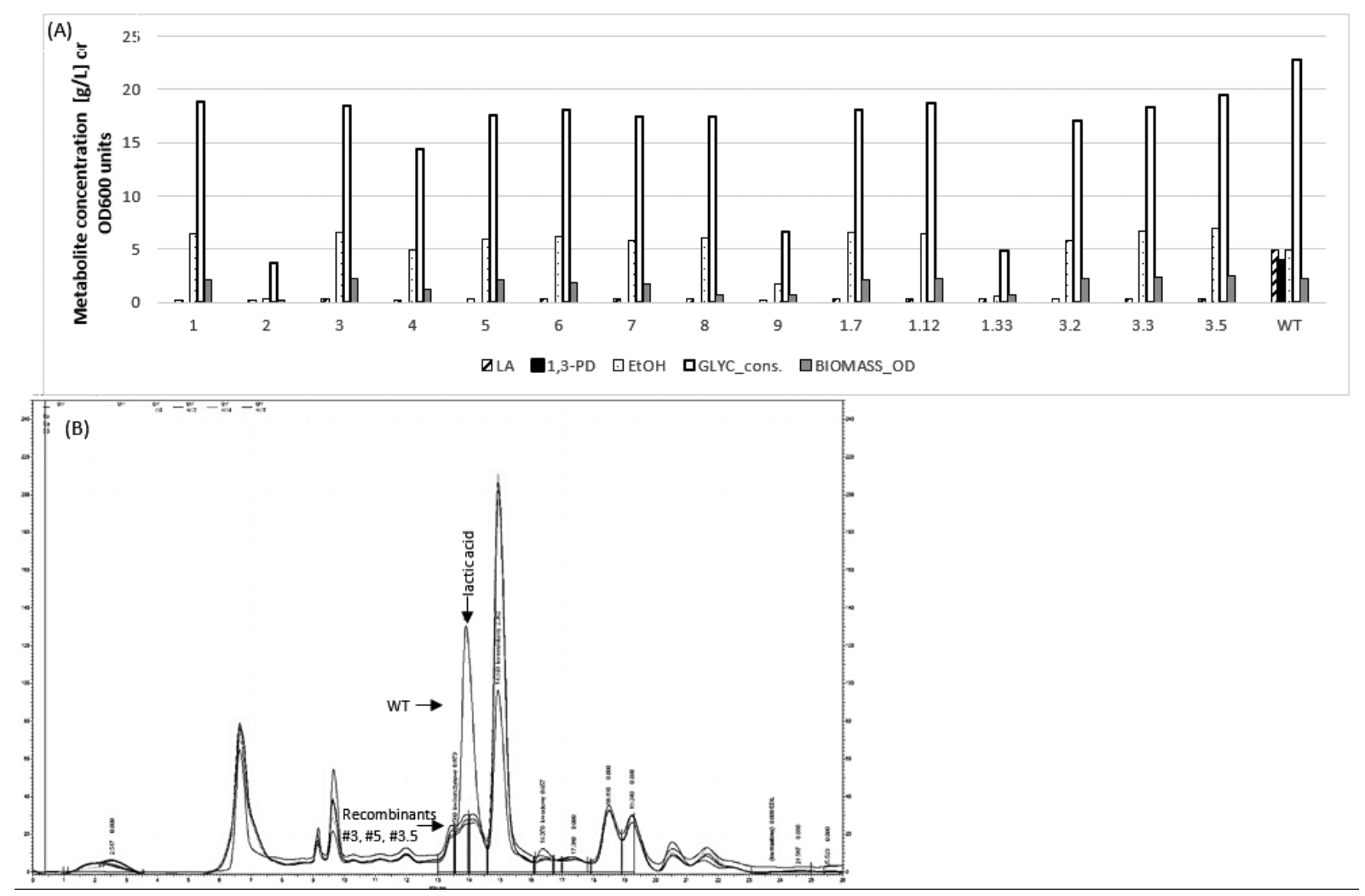

Figure 2. Primary cultivations in B20 medium.

(A) Major metabolites synthesis, biomass production, and substrate utilization by the WT strain and the recombinant strains. The recombinant strains were modified through targeting group II intron into Idh locus, and recovered from LB+kanamycin plate. $X$ axis: individual strains. Y axis: concentration of metabolites in [gL'] , or optical density at $600 \mathrm{~nm}$ wavelength. (B) Exemplary HPLC chromatogram of culture media of WT and the recombinant (\#3, \#5, \#3.5) H. alvei AD27 strains. The strains were cultured in B20 medium, in static conditions, at $30^{\circ} \mathrm{C}$, for $72 \mathrm{~h}$. $\mathrm{X}$ axis: retention time. $Y$ axis: detector readouts. The peak corresponding to LA was marked with an arrow.

was driven through an algorithm implemented in TargeTron ${ }^{\circledR}$ Design on-line tool. In this study we tested two sets of primers provided by the system (see Table 1 set $A$ and $B$ ). Though, due to a very low yield of amplification of the re-targeting fragment generated by the " $\mathrm{B}$ " set of primers (observed as a very thin band in agarose gel), only the re-targeting fragment generated by the "A" set of primers was further used in this study. Insertion site of the Ll.LtrB intron targeted by this set of primers was located at $251 \mathrm{AA}$ of the $H$. alvei $L D H$ sequence. The insertion was targeted in direct proximity of the crucial lysine residue, composing a conserved feature of alpha-hydroxy acid oxidizing enzymes. From the colonies that appeared after transformation on LB+kanamycin agar plates, the largest colonies were subjected to further analyses. The obtained efficiency of transformation was relatively high, resulting in $7.8 \times 10^{\wedge} 3$ colonies per $\mu \mathrm{g}$ of $\mathrm{pACD} 4 \mathrm{~K}-\mathrm{C}$-ldh_targeting_seq plasmid DNA used. Application of more stringent selection pressure (kanamycin at $40 \mu \mathrm{g} / \mathrm{mL}$ ) at the final step of the recombinant strains development, resulted in decrease in the kanamycin-resistant counts $\left(5.3 \times 110^{\wedge} 3\right.$ colonies $/ \mu \mathrm{g}$ of plasmid DNA), but it was still possible to obtain viable kan+ clones.

\section{Primary cultivation tests}

The clones with confirmed disruption of the $l d h$ gene were first cultured in B20 medium (supplemented with kanamycin at $25 \mu \mathrm{g} / \mathrm{mL}$ for the recombinant strains) to verify the phenotype expression (lactate deficiency). The results of primary cultivation tests, comprising biomass growth, glycerol utilization and metabolites production are presented in (Fig. 2A). Only the dominant metabolites (lactate, 1,3-PD, ethanol) present in the culture medium after $72 \mathrm{~h}$ of cultivation were shown and further discussed, since concentration of the remaining compounds was negligible. As presented in (Fig. 2A) some of the recombinant strains (No \#2, \#9, \#1.33) were characterized by severe growth impairment (observed by no biomass accumulation and no glycerol consumption), and these were excluded from further analyses. With respect to the metabolites profile, the primary observation from (Fig. 2A) was that the recombinant strains recovered from LB+kanamycin agar plate were indeed deficient in lactate production, when grown in B20 medium (exemplary chromatogram is shown in (Fig. 2B)). Concomitantly, no 1,3-PD synthesis was observed for these strains, under the applied conditions. Loss of lactate and 1,3-PD formation ability, was coupled with significant increase (approx. 40\%) in ethanol production. Based on these results, three recombinant strains were selected for kinetic analyses of their performance in the B20 medium (Fig. 3). As depicted in (Fig.3) in comparison with the WT strain, the three selected $\Delta \mathrm{ldh}$ strains were all characterized by slower growth and substrate utilization, when cultured in B20 medium. The parental strain entered stationary phase of growth at $48 \mathrm{~h}$ of cultivation, which corresponded to the mid log phase of growth for the recombinant strains. At this time point, the substrate was nearly exhausted in the WT strain cultures, while in the $\Delta \mathrm{ldh}$ strains cultures, more than a half of the initial amount of glycerol was still present in the medium (approx. 13-15 out of $20 \mathrm{~g}$ of glycerol per L). The final 


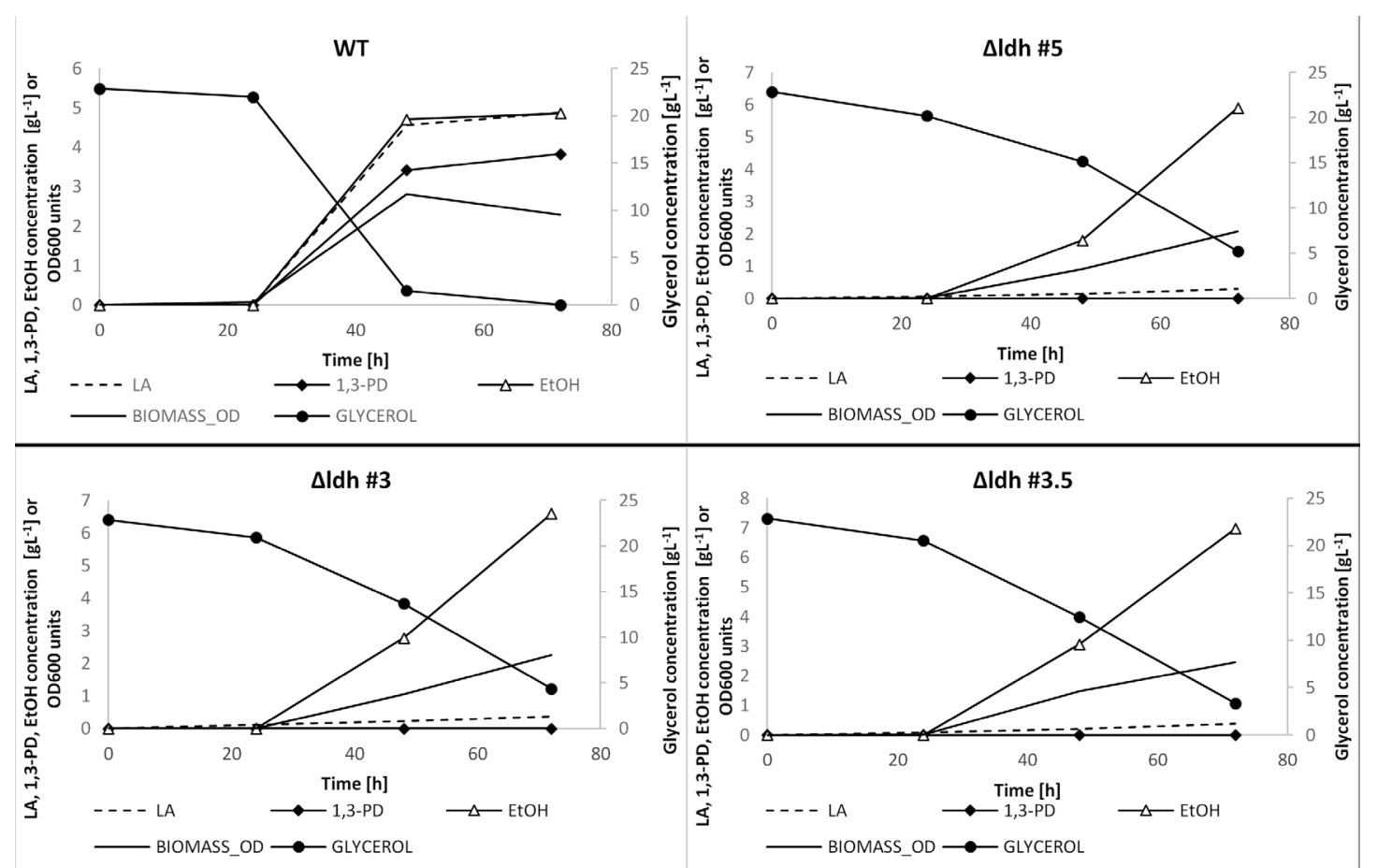

Figure 3. Batch cultivations in B20 medium of the selected H. alvei AD27 strains - WT and the representative $\Delta$ ldh (\#3, \#5, \#3.5) H. alvei AD27 strains.

Production of major metabolites (LA, 1,3-PD, EtOH), glycerol utilization [gL $\left.{ }^{1}\right]$, and accumulation of biomass (OD600). X axis: time of culturing [h]. $Y$ axis: metabolites or glycerol concentration [gL'], OD600 units.

biomass accumulation was slightly lower for the recombinant strains (maximum $\mathrm{OD}_{600}$ value 2.1 to 2.4 ), when compared to the parental strain (maximum $\mathrm{OD}_{600} 2.8$ ). Successful elimination of lactate production was concurrent with unexpected limitation of 1,3-PD synthesis, and increase in ethanol accumulation. After $72 \mathrm{~h}$ of cultivation, the final ethanol concentration reached $6.6 \pm 0.35$, $5.9 \pm 0.33$ and $6.96 \pm 0.36 \mathrm{gL}^{-1}$ for strain \#3, \#5, and \#3.5, compared to $4.86 \pm 0.21 \mathrm{gL}^{-1}$ observed for the WT strain. The ethanol yield for the selected recombinant strains was increased from $0.21 \mathrm{gg}^{-1}$, determined for the W'T strain, up to $0.36,0.34$, and $0.36 \mathrm{gg}^{-1}$ of consumed glycerol, determined for the strain \#3, \#5, and \#3.5, respectively.

\section{Production cultures}

Finally, the $\Delta \mathrm{ldh} H$. alvei strain performance was verified in production cultures, at increased initial glycerol concentration $\left(40 \mathrm{gL}^{-1}\right)$. The $\Delta \mathrm{ldh} \# 5$ strain was selected as a representative of $\Delta \mathrm{ldh}$ phenotype for this experiment. The cultures were conducted in B40 medium, with doubled initial glycerol concentration, when compared to the primary cultivation tests (B20). To get better insight into the recombinant cells physiology, alongside with standard analyses of biomass growth, substrate utilization and metabolites production, the cells were subjected to redox state assessment and intracellular $\mathrm{pH}$ determination through fluorophore staining and flow cytometry analysis. Results of those analyses are shown in (Fig. 4A-C), (Fig. 5) and (Fig. 6). Surprisingly, at higher glycerol concentration, the ability to produce 1,3-PD and lactate was recovered to some extent in the recombinant \#5 strain. 1,3-PD production profile was highly similar between the $\Delta \mathrm{ldh} \# 5$ and WT strains, with respect to both timing and quantity (the final titers: 10.91 $\pm 2.05 \mathrm{vs}$. $10.94 \pm 1.36 \mathrm{gL}^{-1}$, respectively). On the other hand, lactate production, although recovered, was significantly lower for the recombinant \#5 strain $(6.84 \pm 1.1$ vs. $10.38 \pm 1.49$ $\left.\mathrm{gL}^{-1}\right)$. Importantly, when cultured in B40 medium, no significant overproduction of ethanol by the $\Delta \mathrm{ldh} \# 5$ strain was observed $\left(3.09 \pm 0.37\right.$ vs. $2.64 \pm 0.29 \mathrm{gL}^{-1}$, for the recombinant and WT, respectively). The profile of the remaining metabolites (succinate, formate, acetate) was affected by the introduced genetic modification (Fig. 4C), and the recombinant \#5 strain synthesized slightly, but statistically important, higher amounts of all of these by-products. Both biomass formation and glycerol utilization profiles were highly similar for both analyzed strains, with only slight predominance of the WT strain in biomass accumulation, minimized at the end of culturing.

With respect to the intracellular redox potential assessment through flow cytometry analyses, we observed differences in the pattern of subpopulations distribution between the recombinant and the WT strains (Fig. 5). At the beginning of the production cultures, both strains formed dense, relatively homogenous populations with respect to the redox potential (FITC dye emission). Still, the WT cells population was more compact, when compared to $\Delta \mathrm{ldh} \# 5$ strain, which was slightly shifted to the areas of higher redox potential. At the following timepoint $(24 \mathrm{~h})$, WT cell subpopulations pattern was highly similar between the biological triplicates, generating a single, dense population of medium active cells, with a "tail" of highly active cells. On the other hand, the pattern of $\Delta \mathrm{ldh} \# 5$ strain populations was different between the biological triplicates, indicating variability between batches. However, this variability was then surpassed in the next time-point, where the \#5 strain cell populations were all clearly divided into two distinct subpopulations of highly active and lowly active cells. In the WT strain cells populations though, three distinct subpopulations were observed, and this trend was maintained until the end of culturing $(72 \mathrm{~h})$. Also for the \#5 strain, the sub- 

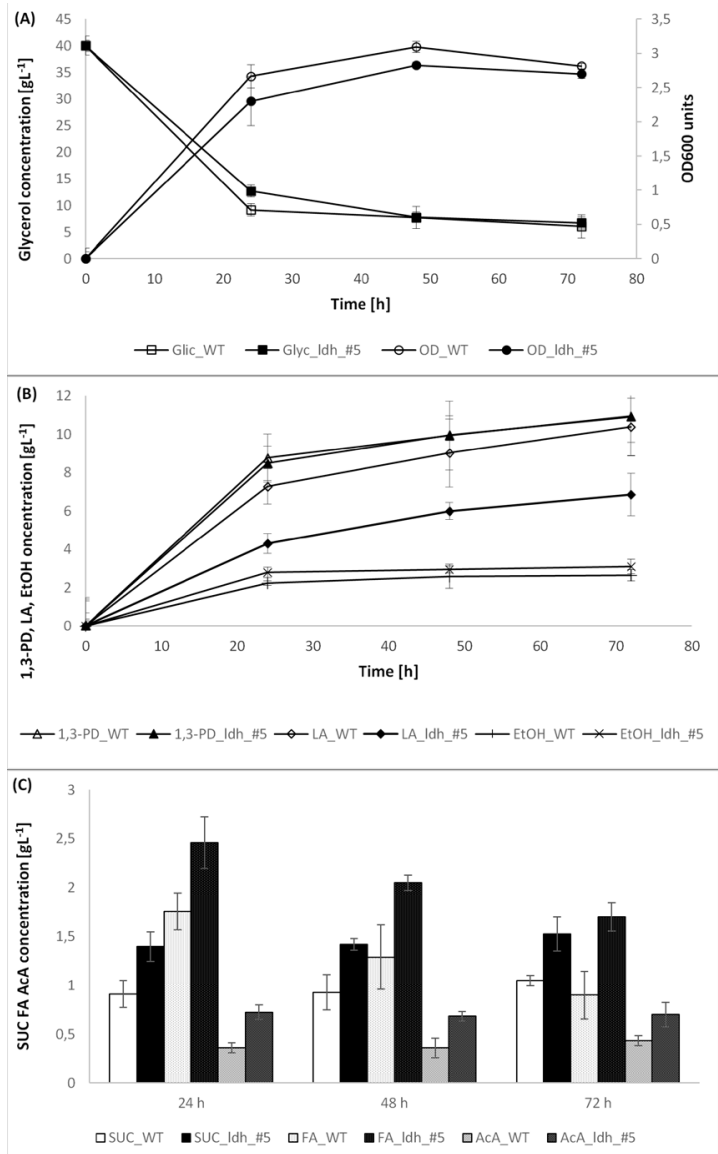

Figure 4. Batch cultivations in B40 medium of the selected H. alvei AD27 strains - WT and the representative $\Delta \mathrm{ldh} \# 5$ strain.

(A) Glycerol utilization [ $\left[\mathrm{gL}^{-1}\right]$, and accumulation of biomass (OD600). (B) Concentration of major metabolites (LA, 1,3-PD, EtOH) $\left[\mathrm{gL}^{-1}\right]$. (C) Concentration of minor metabolites (SUC, FA, AcA) $\left[g^{-1}\right]$. $X$ axis: time of culturing (A) (B) or time-points of the culture $(C)[\mathrm{h}]$. $Y$ axis: metabolites or glycerol concentration $\left[\mathrm{gL}^{-1}\right]$, OD600 units. populations pattern generated at $48 \mathrm{~h}$ (division into two subpopulations) remained unaltered until the last timepoint. Nevertheless, the overall population readouts of FITC dye fluorescence emission were higher for the WT cells populations (shift towards high FITC emission area), suggesting higher metabolic activity and redox potential of these cells, which were maintained until the end of the production cultures. For the recombinant $\Delta \mathrm{ldh} \# 5$ strain, the metabolic activity was lower, since higher fraction of the population was shifted towards low activity area in the cytographs.

High similarity of the WT and $\Delta \mathrm{ldh} \# 5$ strains performance in B40 medium, expressed as their growth kinetics and metabolites formation, was concomitant with corresponding profiles of intracellular $\mathrm{pH}$ (Fig. 6). Indeed, no significant differences in this parameter were observed for both analyzed strains throughout the cultures duration. The only difference was noted at the beginning of the production cultures $(0 \mathrm{~h})$, where the recombinant strain was characterized by slightly less acidic cytosolic $\mathrm{pH}$ ( $\mathrm{pH} \sim 6.8 v$ s. $\sim 6.5$ ). Subsequently, the $\mathrm{pH}$ profile was consistent between WT and \#5 cells populations. While at the beginning of the production cultures, the cytoplasm of the analyzed cells was more acidic, along with the culture duration, the intracellular $\mathrm{pH}$ increased, and stabilized at $48 \mathrm{~h}$ of culturing.

\section{DISCUSSION}

Clostridium and Klebsiella species are still the major players in biotechnological 1,3-PD production. Nonetheless, alternative biocatalysts, belonging to Hafnia, Citrobacter or Lactobacillus genera, are being explored in this regard (Drożdżyńska et al., 2014; Kang et al., 2014; Metsoviti et al., 2013; Pflügl et al., 2014; Ricci et al., 2015). Our interest in $H$. alvei AD27 strain as 1,3-PD producer stems from several advantageous traits of this species, especially over $K$. pneumoniae strains. Foremost, $H$. alvei belongs to the first hazard group (http://www.lgcstandards-atcc. $\operatorname{org} /$ ), which is of substantial importance with respect to
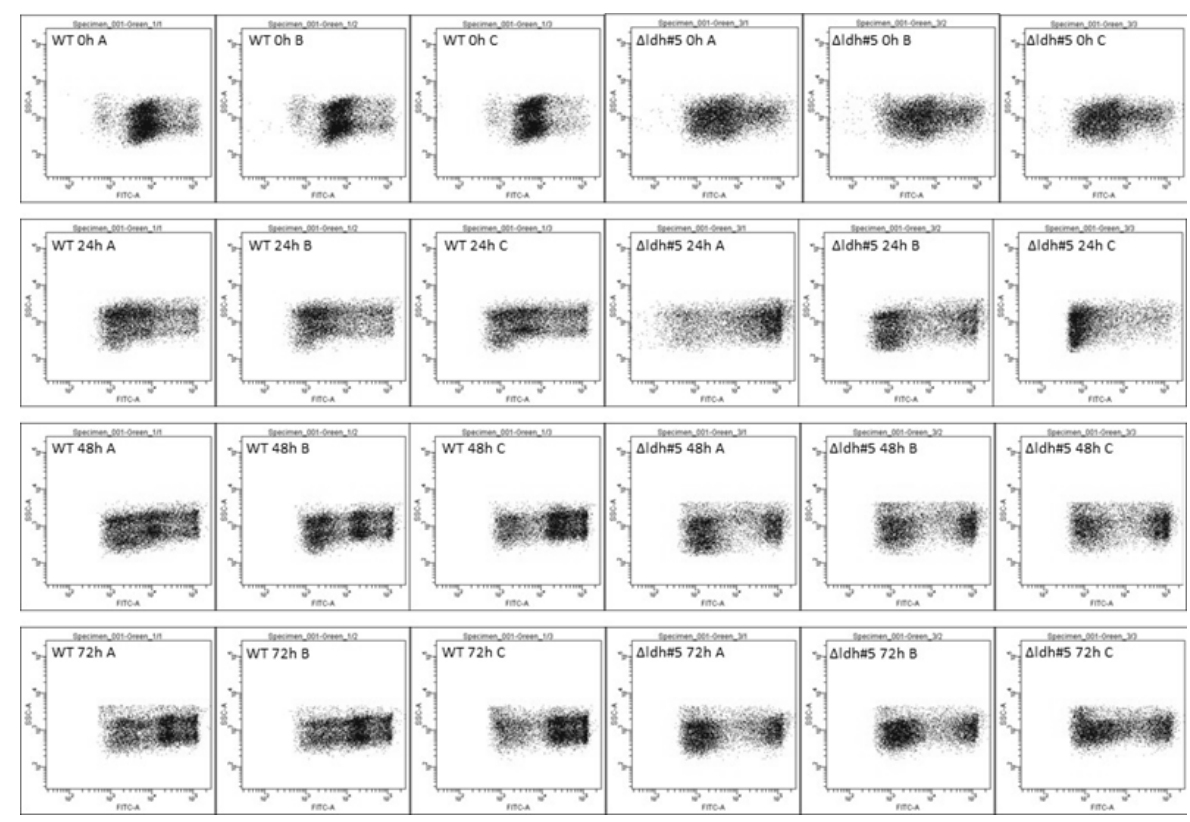

Figure 5. Cytographs (scatter plots) illustrating distribution of redox potential in populations of WT and $\Delta$ ldh\#5 H. alvei AD27 cells at different time-points of the production culture (B40 medium).

In each individual cytograph: $x$ axis: distribution of cellular elements, depending on fluorescence emission from FITC dye (vitality); $y$ axis: distribution of cellular elements, depending on their SSC-A parameter (size and granularity). A, B, C - individual repetitions of biological triplicate. 


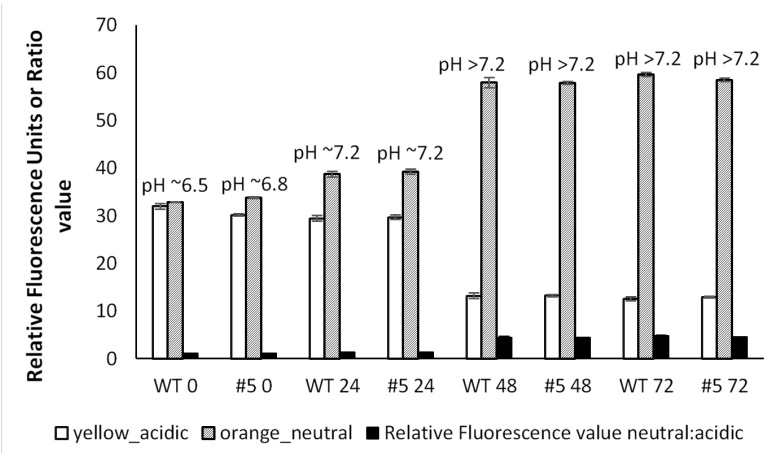

Figure 6. Intracellular $\mathrm{pH}$ measurements using flow cytometry analysis in populations of WT and $\Delta \mathrm{ldh} \# 5 \mathrm{H}$. alvei AD27 cells at different time-points of production culture (B40 medium).

The intracellular $\mathrm{pH}$ was assesses based on the relative ratio of fluorescence emission by the two dyes (yellow-acidic and orange-neutral). $X$ axis: WT or $\Delta \mathrm{ldh} \# 5$ strains at different timepoints. $Y$ axis: fluorescence intensity or ratio of fluorescence intensities.

the laboratory safety procedures, as well as the industrial process development. Second of all, in K. pneumoniae, conversion of glycerol to 1,3-PD is coupled with formation of high quantities of 2,3-butanediol (Ji et al., 2009). 2,3-Butanediol, besides being a valuable chemical of numerous industrial applications (Celińska \& Grajek, 2009), hampers purification process when present together with 1,3-PD in the culture medium, due to similar boiling points of these chemicals (Hao et al., 2006; Xiu and Zeng, 2008; Anand et al., 2011). In contrast, H. alvei AD27 strain gives a negative result in Voges-Proskauer test (Drożdżyńska et al., 2014), indicating lack of acetoin synthesis, the direct intermediate of 2,3-butanediol. Moreover, in all the chromatography analysis accompanying this work, we did not identified 2,3-BD among the metabolites being produced by $H$. alvei AD27 strain.

Bacterial group II introns have been used as controllable gene targeting tools in several non-model species, like Clostridium (Chen et al., 2005a; Heap et al., 2007), Lactococcus (Chen et al., 2005b; Frazier et al., 2003), Shigella and Salmonella (Karberg et al., 2001), or Staphylococcus (Yao et al., 2006). Insertion of group II introns into the desired locus is site-specific, due to an algorithm-designed re-targeting sequence developed in a course of the protocol. One of the most important traits adding to the system's versatility is independence of the intron operation from genetic background of the host system, since the activities required for the intron action are encoded within its own sequence. This feature predominantly contributed to applicability of the group II intron-based systems in the under-described species. The Targe'Tron ${ }^{\circledR}$ tool used in this study, apart from its indigenous broad host range, possesses another advantageous trait. This system offers convenient method of selection of successfully integrated introns, as it is coupled with acquisition of a dominant trait - kanamycin resistance. Such a feature was obtained by integration of a kanamycin resistance gene interrupted by a self-splicing group I intron into the retro-homing group II intron (Zhong et al., 2003).

Homologous recombination-based systems were adopted to direct targeted gene knock-outs in wild-type Klebsiella strains, with the aim of 1,3-PD production enhancement and/or elimination of excessive by-products formation (Horng et al., 2010; Seo et al., 2009; Xu et al., 2009; Yang et al., 2007; Zhang et al., 2006). Elimination of the major lactate dehydrogenase $(\mathrm{LDH})$ activity, $l d h A$, was proved to be a successful strategy for improvement of 1,3-PD production in K. pneumoniae (Xu et al., 2009) and K. oxytoca (Yang et al., 2007). In both of these studies, it was possible to nearly fully eliminate lactate synthesis in the constructed recombinant strains. In the present study, we were able to reach only a decrease in lactate accumulation in the batch production cultures of $H$. alvei AD27. One of the potential reasons that could contribute to such an outcome was targeting the LDH-encoding gene that was replaced by the other LDH isozyme, encoded within the $H$. alvei AD27 genome. In comparison to Klebsiella species, $H$. alvei is an under-described species with respect to gene assignment and availability of data on enzymatic activities involved in glycerol fermentation. According to Klebsiella Genome Sequencing Project, four $\mathrm{LDH}$-encoding genes are present in the species genome, and $l d h A$-encoded fermentative D-lactate dehydrogenase is the major activity contributing to NADH recycling (Tarmy \& Kaplan, 1968a and b). LDHA was shown to be activated during fermentation in $K$. pneumoniae (Zheng et al., 2008). In this study, we targeted the $l d h$ sequence from $H$. alvei genome, available in GenBank under accession number CP009706.1, with the highest similarity to the $l d h A$ sequence from $K$. pneumoniae. Disruption of $l d h A$ sequence, entailed nearly full abolition of lactate formation in Klebsiella strains (Xu et al., 2009; Yang et al., 2007). Obviously, in $H$. alvei cells some LDH isozymes could replace to some extent the lacking $\mathrm{LDH}$ activity in the $\Delta$ ldh genetic background, probably to maintain redox homeostasis and stabilize internal $\mathrm{pH}$ (as shown in Fig. 6).

In the study by $\mathrm{Xu}$ et al. (2009), following the $l d h A$ gene disruption, lactate accumulation was limited to $6 \%$ of the initial quantity produced by the parental strain (94\% reduction in the lactate synthesis). Simultaneously, the final 1,3-PD concentration was improved by only $7 \%$, during fed-batch cultivations in that study. The introduced modification contributed to substantial redistribution of the carbon fluxes between individual metabolic pathways, triggering increased accumulation of ethanol (3-fold increase), succinate (50\% increase), and 2,3-butanediol (2-fold increase), and reduction in acetate accumulation ( $40 \%$ reduction). In contrast, the same strategy applied to $K$. oxytoca strain, triggered as high as $45 \%$ increase in 1,3-PD production in fed-batch anaerobic cultivations. The carbon flux distribution was markedly changed, but the observed profile of the metabolites was different from what was observed for the $\Delta \mathrm{ldhA}$ K. pneumoniae $(80 \%$ increase in succinate, $30 \%$ increase in ethanol, $15 \%$ increase in acetate, and $73 \%$ increase in 2,3-butanediol).

In the present study, the observed metabolite profiles resulting from $\Delta \mathrm{ldh}$ modification in $H$. alvei $\mathrm{AD} 27$, varied significantly depending on the initial glycerol concentration applied in the culture medium. When $H$. alvei AD27 was cultured in B20 medium, deletion of $l d h$ gene triggered up to $40 \%$ increase in ethanol accumulation, and nearly full abolition of 1,3-PD and lactate production. In the study by Zhang et al. (2008), metabolic flux analysis in K. pneumoniae proved that formation of ethanol reduces 1,3-PD production due to competence for reducing equivalents by the two distal dehydrogenases. Thus, increased ethanol synthesis could most probably consume significant proportion of the NADH, recovered by $l d h$ gene knock-out, disabling efficient production of 1,3-PD under low glycerol concentrations. Under higher glycerol concentrations (B40 medium), the ability to synthesize 1,3-PD was recovered in the $\Delta \mathrm{ldh} \# 5 H$. alvei. The promoting role of elevated glycerol concentrations on 1,3-PD formation were earlier explained by Zhang et 
al. (2008), and also correlated with increased expression of the genes encoded by dha regulon. In that report it was demonstrated that higher glycerol concentrations promote 1,3-PD synthesis restraining formation of some of the oxidative branch metabolites, like ethanol. Correspondingly, in the present study, application of higher glycerol concentrations lead to nearly 3 -fold increase in 1,3-PD titer of the WT strain, and recovered the $\Delta \mathrm{ldh}$ \#5 strain's ability to produce 1,3-PD, up to the W'T strain level. When cultured in B40 medium, both strains WT and $\Delta \mathrm{ldh} \# 5$ accumulated nearly the same amounts of ethanol, which marked a clear shift from ethanol to 1,3-PD formation under elevated glycerol concentrations. Increased initial glycerol concentration also recovered the $\Delta \mathrm{ldh} \# 5$ strain ability to produce lactate. Nevertheless, its concentration remained significantly lower in the \#5 strain cultures, indicating that $\Delta \mathrm{ldh}$ genotype was operable, but probably some $L D H$ isozymes could replace to some extent the knocked-out activity.

While the final titers of 1,3-PD and EtOH were highly similar for the WT and the \#5 strains in B40 medium cultures, the remaining metabolite profiles were changed upon $\Delta$ ldh modification in $H$. alvei AD27. The production of succinate, formate, and acetate was enhanced by approx. $45 \%, 90 \%$, and $60 \%$ for the \#5 recombinant strain, when compared with its WT counterpart. Noteworthy, the distal metabolic pathways leading to the two "increased" by-products, formate and acetate, did not compete for reducing equivalents with 1,3-PD formation, leaving succinate pathway compensating for surplus $\mathrm{NADH}$ consumption in $\Delta \mathrm{ldh}$ strain, as the ethanol levels remained unaffected. The crucial role of balancing reducing equivalents for development of a desired metabolite profile was recently dealt with by Cui et al. (2014). In that study, through elimination of NADH-consuming pathways in K. pneumoniae, leading to 2,3-butanediol and lactate, the internal redox status (NADH:NAD+ ratio) was significantly increased. Subsequent overexpression of 1,3-PD dehydrogenase gene enabled sequestration of the excessive NADH pool for 1,3-PD formation, normalizing the NADH:NAD+ ratio to the WT level.

$\mathrm{Xu}$ et al. (2009) reported improved yield of 1,3PD from glycerol in fed-batch cultures (0.52 vs. 0.48 molmol ${ }^{-1}$ ) as a result of $l d h A$ gene knock-out in $K$. pneumoniae. Correspondingly, a great improvement in the final yield of 1,3-PD formation from glycerol (0.53 vs. $0.41 \mathrm{~mol} \mathrm{~mol}^{-1}$ ) was observed under $l d h A$ gene deletion in $K$. oxytoca strain, cultured under anaerobic conditions (Yang et al., 2007). On the other hand, deletion of $l d h A$ gene concomitant with $\triangle \mathrm{budA}+\mathrm{B}$ modification (abolition of 2,3-butanediol synthesis), lead to decrease in the 1,3PD yield (0.61 vs. $\left.0.59 \mathrm{~mol} \mathrm{~mol}^{-1}\right)$, and further modifications, namely 1,3-PD dh overexpression, did not recover the yield to the WT level (0.61 vs. $0.6 \mathrm{~mol} \mathrm{~mol}^{-1}$ ) (Cui et al., 2014). As suggested by the authors, an increase in the other oxidative branch metabolites formation disallowed improvement of this parameter. In our study, the yield of 1,3-PD (0.4 vs. $\left.0.39 \mathrm{~mol} \mathrm{~mol}^{-1}\right)$ remained basically unaffected, by the introduced modification. It obviously appeared that the cell could compensate for the lowered lactate production, by enhanced accumulation of the other products of the oxidative branch of the glycerol dissimilation pathway (Fig. 4C).

The fluorophore staining and flow cytometry analyses accompanying this work demonstrated lack of important differences in the internal $\mathrm{pH}$ parameter that could explain the observed alterations in $\Delta$ ldh phenotype. The observed variation in the redox potential of $\Delta \mathrm{ldh} \# 5$ strain populations at $24 \mathrm{~h}$ of production culture could result from slight time shift between independent batches at entering logarithmic phase of growth (compare Fig. 4A and Fig. 5). This observation was also reflected by the amount of accumulated biomass, as \pm S.D. bar is relatively high at this time-point in (Fig. 4A), indicating variations in the independent culture runs, which were further surpassed at the following time-point. The ultimate conclusions from the redox potential measurements are that the recombinant $\Delta$ ldh \#5 strain was characterized by lower vitality than the WT strain, but it was not reflected by slower growth nor substrate utilization, as it could be expected.

In conclusion, this is the first report on construction of $\Delta \mathrm{ldh} H$. alvei strain, using group II intron, with the aim of lowering lactate formation during 1,3-PD production. The results presented in this paper demonstrated that the ultimate outcomes of $\Delta \mathrm{ldh}$ modification depended on the culture medium used (high or low initial glycerol concentration). Under 1,3-PD production promoting conditions (high glycerol load), the obtained $\Delta \mathrm{ldh}$ \#5 strain was characterized by lower lactate production, retaining similar growth characteristics and 1,3-PD formation profile. The titers of the remaining metabolites (succinate, formate, acetate) were modified upon $\Delta \mathrm{ldh}$ modification. The internal $\mathrm{pH}$ remained unaltered after $l d h$ knock-out, but the overall vitality of the recombinant cells population was lower, when compared to the WT strain.

\section{Acknowledgements}

This research was funded by the project No 01.01.0200-074/09 co-funded by The European Union from The European Regional Development Fund within the framework of the Innovative Economy Operational Programme 2007-2013.

\section{REFERENCES}

Ahrens K, Menzel K, Zeng AP, Deckwer WD (1998) Kinetic, dynamic, and pathway studies of glycerol metabolism by Klebsiella pneumoniae in anaerobic continuous culture: III. Enzymes and fluxes of glycerol dissimilation and 1,3-propanediol formation. Biotechnol Bioeng 59: 544-552. http://doi.org/ 10.1002/(SICI)10970290(19980905) 59:53.0

Anand P, Saxena RK, Marwah RG (2011) A novel downstream process for 1,3-propanediol from glycerol-based fermentation. Appl Microbiol Biotechnol 90: 1267-1276. http://doi.org/10.1007/s00253-011-3161-2

Barbirato F, Camarasca-Claret C, Bories A, Grivet JP (1995) Description of the glycerol fermentation by a new 1,3-propanediol producing microorganism: Enterobacter agglomerans. Appl Microbiol Biotechnol 43: 786-793. http://doi.org/10.1007/bf02431909

Biebl H, Zeng AP, Menzel K, Deckwer WD (1998) Fermentation of glycerol to 1,3-propanediol and 2,3-butanediol by Klebsiella pneumoniae Appl Microbiol Biotechnol 50: 24-29. http://doi.org/10.1007/ s002530051251

Celińska E (2010) Debottlenecking the 1,3-propanediol pathway by metabolic engineering. Biotechnol Adv 28: 519-530. http://doi. org/10.1016/j.biotechadv.2010.03.003

Celińska E (2012) Klebsiella spp. as a 1,3-propanediol producer - the metabolic engineering approach. Crit Rev Biotechnol 32: 274-288. http://doi.org/ 10.3109/07388551.2011.616859

Celińska E (2015a) Fully glycerol-independent microbial production of 1,3 -propanediol via non-natural pathway: paving the way to success with synthetic tiles. Biotechnol J 10: 242-243, http://doi.org/10.1002/ biot. 201400360

Celińska E, Drożdżyńska A, Jankowska M, Białas W, Czaczyk K, Grajek W (2015b) Genetic engineering of Citrobacter freundii AD970 strain towards enhanced 1,3-propanediol production. Process Biochem 50: 48-60. http://doi.org/10.1016/j.procbio.2014.09.001

Celińska E, Grajek W (2013) A novel multigene expression construct for modification of glycerol metabolism in Yarrowia lipolytica. Microbial Cell Factories 12: 102. http://doi.org/ 10.1186/1475-2859-12-102

Celinska E, Grajek W (2009) Biotechnological production of 2,3-butanediol - current state and prospects. Biotechnol Adv 27: 715-725. http://doi.org/ 10.1016/j.biotechadv.2009.05.002 
Chen Y, McClane BA, Fisher DJ, Rood JI, Gupta P (2005a) Construction of an alpha toxin gene knockout mutant of Clostridium perfringens type A by use of a mobile group II intron. Appl Environ Microbiol 71: 7542-7547. http://doi.org/ 10.1128/AEM.71.11.7542-7547.2005

Chen Y, Klein JR, McKay L.L, Dunny GM (2005b) Quantitative analysis of group II intron expression and splicing in Lactococcuslactis. Appl Environ Microbiol 71: 2576-2586. http://doi.org/ 10.1128/ AEM.71.5.2576-2586.2005

Chen Z, Geng F, Zeng AP (2015) Protein design and engineering of a de novo pathway for microbial production of 1,3-propanediol from glucose. Biotechnol J 10: 284-289. http://doi.org/ 10.1002/ biot. 201400235

Cheng KK, Liu HJ, Liu DH (2005) Multiple growth inhibition of Klebsiella pneumoniae in 1,3-propanediol fermentation Biotecbnol Lett 27: 19-22. http://doi.org/10.1007/s10529-004-6308-8

Cui YL, Zhou JJ, Gao LR, Zhu CQ, Jiang X, Fu SL, Gong H (2014) Utilization of excess NADH in 2,3-butanediol-deficient Klebsiella pneumoniae for 1,3-propanediol production. J Appl Microbiol 117: 690698. http://doi.org/ 10.1111/jam.12588

Dietz D, Zeng AP (2014) Efficient production of 1,3-propanediol from fermentation of crude glycerol with mixed cultures in a simple medium. Bioprocess Biosyst Eng 37: 225-233. http://doi.org/ 10.1007/ s00449-013-0989-0

Drożdżyńska A, Pawlicka J, Kubiak P, Kośmider A, Pranke D, Olejnik-Schmidt A, Czaczyk K (2014) Conversion of glycerol to 1,3-propanediol by Citrobacterfreundii and Hafnia alvei - newly isolated strains from the Enterobacteriaceae. N Biotechnol 31: 402-4010. http:// doi.org/ 10.1016/i.nbt.2014.04.002

Frazier CL, San Filippo J, Lambowitz AM, Mills DA (2003) Genetic manipulation of Lactococcus lactis by using targeted group II introns: generation of stable insertions without selection. Appl Environ Microbiol 69: 1121-1128. http://doi.org/10.1128/AEM.69.2.11211128.2003

Guo X, Fang H, Zhuge B, Zong H, Song J, Zhuge J, Du X (2013) budC knockout in Klebsiella pneumoniae for bioconversion from glycerol to 1,3-propanediol Biotechnol Appl Biochem 60: 557-563. http:// doi.org/ 10.1002/bab.1114

Hao J, Xu F, Liu HJ, Liu DH (2006) Downstream processing of 1,3-propanediol fermentation broth. J Chem Technol Biotechnol 81: 102-108. http://doi.org/10.1002/jctb.1369

Heap JT, Pennington OJ, Cartman ST, Carter GP, Minton NP (2007) The ClosTron: a universal gene knock-out system for the genus Clostridium. J Microbiol Methods 70: 452-464. http://doi.org/ 10.1016/j.mimet.2007.05.021

Homann T, Tag C, Biebl H, Deckwer WD, Schink B (1990) Fermentation of glycerol to 1,3-propanediol by Klebsiella and Citrobacter strains. Appl Microbiol Biotechnol 33: 121-126. http://doi.org/ 10.1007/BF00176511

Hong WK, Kim CH, Heo SY, Luo LH, Oh BR, Rairakhwada D, Seo JW (2011) 1,3-Propandiol production by engineered Hansenula polymorpha expressing dhagenes from Klebsiella pneumoniae. Bioprocess Biosyst Eng 34: 231-236. http://doi.org/10.1007/s00449-010-0465-z

Horng YT, Chang KC, Chou TC, Yu CJ, Chien CC, Wei YH, Soo PC (2010) Inactivation of $d h a D$ and dhaK abolishes by-product accumulation during 1,3-propanediol production in Klebsiella pneumoniae. J Ind Microbiol Biotechnol 37: 707-716. http://doi.org/ 10.1007/ s10295-010-0714-9

Ji XJ, Huang H, Zhu JG, Hu N, Li S (2009) Efficient 1,3-propanediol production by fed-batch cultureof Klebsiella Pneumoniae: the role of $\mathrm{pH}$ fluctuation. Appl Biochem Biotechnol 159: 605-613. http://doi.org/ 10.1007/s12010-008-8492-9

Kaeding T, DaLuz J, Kube J, Zeng AP (2015) Integrated study of fermentation and downstream processing in a miniplant significantly improved the microbial 1,3-propanediol production from raw glycerol. Bioprocess Biosyst Eng 38: 575-586. http://doi.org/ 10.1007/ s00449-014-1297-z

Kang TS, Korber DR, Tanaka T (2014) Bioconversion of glycerol to 1,3-propanediol in thin stillage-based media by engineered Lactobacillus panis PM1. J Ind Microbiol Biotechnol 41: 629-635. http://doi.org/ 10.1007/s10295-014-1403-x

Kaur G, Srivastava AK, Chand S (2013) Bioconversion of glycerol to 1,3-propanediol: a mathematical model-based nutrient feeding approach for high production using Clostridium diolis. Bioresour Tecbnol 142: 82-87. http://doi.org/ 10.1016/j.biortech.2013.05.040

Karberg M, Guo H, Zhong J, Coon R, Perutka J, Lambowitz AM (2001) Group II introns as controllable gene targeting vectors for genetic manipulation of bacteria. Nat Biotechnol 19: 1162-1167. http://doi.org/ 10.1038/nbt1201-1162

Kumar V, Sankaranarayanan M, Durgapal M, Zhou S, Ko Y, Ashok S, Sarkar R, Park S (2013) Simultaneous production of 3-hydroxypropionic acid and 1,3-propanediol from glycerol using resting cells of the lactate dehydrogenase-deficient recombinant Klebsiella pneumoniae overexpressing an aldehyde dehydrogenase. Bioresour Tecbnol 135: 555-563. http://doi.org/ 10.1016/i.biortech.2012.11.018

Kumar V, Sankaranarayanan M, Jae KE, Durgapal M, Ashok S, Ko Y, Sarkar R, Park S (2012) Co-production of 3-hydroxypropionic acid and 1,3-propanediol from glycerol using resting cells of recombinant Klebsiella pneumoniae J2B strain overexpressing aldehyde dehydrogenase. Appl Microbiol Biotechnol 96: 373-383. http://doi.org/ $10.1007 / \mathrm{s} 00253-012-4187-9$

Liang Q, Zhang H, Li S, Qi Q (2011) Construction of stress-induced metabolic pathway from glucose to 1,3-propanediol in Escherichia coli. Appl Microbiol Biotechnol 89: 57-62. http://doi.org/ 10.1007/ s00253-010-2853-3

Lin ECC (1976) Glycerol dissimilation and its regulation in bacteria. Aппи RevMicrobiol 30: 535-578. http://doi.org/ 10.1146/annurev. mi.30.100176.002535

Ma Z, Bian Y, Shentu X, Yu X (2013) Development of a novel recombinant strain Zygosacharomyces rouxii JL2011 for 1,3-propanediol production from glucose. Appl Microbiol Biotechnol 97: 4055-4064. http://doi.org/ 10.1007/s00253-012-4501-6

Maervoet VE, De Maeseneire SL, Avci FG, Beauprez J, Soetaert WK, De Mey M (2014) 1,3-propanediol production with Citrobacterwerkmanii DSM17579: effect of a dhaD knock-out. Microb Cell Fact 13: 70. http://doi.org/ 10.1186/1475-2859-13-70

Metsoviti M, Zeng AP, Koutinas AA, Papanikolaou S (2013) Enhanced 1,3-propanediol production by a newly isolated Citrobacterfreundii strain cultivated on biodiesel-derived waste glycerol through sterile and non-sterile bioprocesses J Biotechnol 163: 408-418. http://doi. org/ 10.1016/j.jbiotec.2012.11.018

Nakamura C, Whited G (2003) Metabolic engineering for the microbial production of 1,3-propanediol. Curr Opin Biotechnol 14: 454-459. http://doi.org/10.1016/j.copbio.2003.08.005

Oh BR, Seo JW, Heo SY, Luo LH, Hong WK, Park DH, Kim CH (2013) Efficient production of 1,3-propanediol from glycerol upon constitutive expression of the 1,3-propanediol oxidoreductase gene in engineered Klebsiella pneumoniae with elimination of by-product formation. Bioprocess Biosyst Eng 36: 757-763. http://doi.org/ 10.1007/s00449-013-0901-y

Pflügl S, Marx H, Mattanovich D, Sauer M (2014) Heading for an economic industrial upgrading of crude glycerol from biodiesel production to 1,3-propanediol by Lactobacillus diolivorans. Bioresour Technol 152: 499-504. http://doi.org/ 10.1016/j.biortech.2013.11.041

Rao Z, Ma Z, Shen W, Fang H, Zhuge J, Wang X (2008) Engineered Saccharomyces cerevisiae that produces 1,3-propanediol from D-glucose. J Appl Microbiol 105: 1768-1776. http://doi.org/ 10.1111/j.13652672.2008.03868.x

Ricci MA, Russo A, Pisano I, Palmieri L, de Angelis M, Agrimi G (2015) Improved 1,3-Propanediol Synthesis from Glycerol by the Robust Lactobacillus renteri Strain DSM 20016. J Microbiol Biotechnol 25: 893-902. http://doi.org/10.4014/jmb.1411.11078

Rodriguez A, Woitusik M, Ripoll V, Santos VE, Garcia-Ochoa F (2016) 1,3-Propanediol production from glycerol with a novel biocatalyst Shimwelliablattae ATCC 33430: Operational conditions and kinetics in batch cultivations. Bioresour Tecbnol 200: 830-837. http:// doi.org/ 10.1016/j.biortech.2015.10.061

Sabra W, Groeger C, Zeng AP (2016) Microbial Cell Factories for Diol Production. Adv Biochem Eng Biotechnol 155: 165-197. http://doi.org/ $10.1007 / 10 \_2015 \quad 330$

Sambrook J, Fritsch EF, Maniatis T (1989) Molecular cloning: A laboratory manual 2nd edition. Cold Spring Harbor, NY: Cold Spring Harbor Laboratory Press

Saxena RK, Anand P, Saran S, Isar J (2009) Microbial production of 1,3-propanediol: Recent developments and emerging opportunities. Biotechnol $A d v$ 27: 895-913. http://doi.org/ 10.1016/j.biotechadv.2009.07.003

Seo MY, Seo JW, Heo SY, Baek JO, Rairakhwada D, Oh BR, Seo PS, Choi MH, Kim CH (2009) Elimination of by-product formation during production of 1,3-propanediol in Klebsiella pneumoniae by inactivation of glycerol oxidative pathway. Appl Microbiol Biotechnol 84: 527-534. http:// doi.org/ 10.1007/s00253-009-1980-1

Tarmy EM, Kaplan NO (1968a) Chemical characterization of D-lactate dehydrogenase from Eschericbia coli. B J Biol Chem 243: 2579-2586

Tarmy EM, Kaplan NO (1968b) Kinetics of Eschericbia coli B D-lactate dehydrogenase and evidence for pyruvate-controlled change in conformation. J Biol Chem 243: 2587-2596

Wu Z, Wang Z, Wang G, Tan T (2013) Improved 1,3-propanediol production by engineering the 2,3-butanediol and formic acid pathways in integrative recombinant Klebsiella pneumoniae. J Biotechnol 168: 194-200. http://doi.org/ 10.1016/j.j.jiotec.2013.04.022

Xiu ZL, Zeng AP (2008) Present state and perspective of downstream processing of biologically produced 1,3-propanediol and 2,3-butanediol. Appl Microbiol Biotecbnol 78: 917-926. http://doi.org/ 10.1007/ s00253-008-1387-4

Xu YZ, Guo NN, Zheng ZM, Ou XJ, Liu HJ, Liu DH (2009) Metabolism in 1,3-Propanediol Fed-Batch Fermentation by a D-Lactate Deficient Mutant of Klebsiella pneumoniae. Biotechnol Bioeng 104: 965972. http://doi.org/ 10.1002/bit.22455.

Yang G, Tian J, Li J (2007) Fermentation of 1,3-propanediol by a lactate deficient mutant of Klebsiellaoxytoca under microaerobic conditions. Appl Microbiol Biotechnol 73: 1017-1024. http://doi.org/ 10.1007/s00253-006-0563-7 
Yao J, Zhong J, Fang Y, Geisinger E, Novick RP, Lambowitz AM (2006) Use of targetrons to disrupt essential and nonessential genes in Staphylococcus aureus reveals temperature sensitivity of Ll.LtrB group II intron splicing. RNA 12: 1271-1281. http://doi.org/ $10.1261 /$ rna.68706

Zeng AP, Biebl H (2002) Bulk chemicals from biotechnology: the case of 1,3-propanediol production and the new trends. Adv Biochem Eng Biotechnol 74: 239-259. http://doi.org/10.1007/3-540-45736-4

Zeng AP, Biebl H, Schlieker H, Deckwer WD (1993) Pathway analysis of glycerol fermentation by Klebsiella pneumoniae: Regulation of reducing equivalent balance and product formation. Enzyme Microb Technol 15: 770-779. http://doi.org/10.1016/0141-0229(93)90008-P

Zeng AP, Sabra W (2011) Microbial production of diols as platform chemicals: recent progresses. Curr Opin Biotechnol 22: 749-757. http://doi.org/ 10.1016/j.copbio.2011.05.005

Zhang Y, Li Y, Du C, Liu M, Cao Z (2006) Inactivation of aldehyde dehydrogenase: a key factor for engineering 1,3-propanediol production by Klebsiella pneumoniae. Metab Eng 8: 578-586. http://doi.org/ 10.1016/j.ymben.2006.05.008
Zhang Q, Teng H, Sun Y, Xiu Z, Zeng AP (2008) Metabolic flux and robustness analysis of glycerol metabolism in Klebsiella pneumoniae. Bioprocess Biosyst Eng 31: 127-135. http://doi.org/10.1007/3-54045736-4

Zheng P, Wereath K, Sun J, Van den Heuve IJ, Zeng AP (2006) Overexpression of genes of the dha regulon and its effects on cell growth, glycerol fermentation to 1,3-propanediol and plasmid stability in Klebsiella pneumoniae. Process Biochem 41: 2160-2169. http://doi. org/10.1016/j.procbio.2006.06.012

Zheng ZM, Xu YZ, Liu HJ, Guo NN, Cai ZZ, Liu DH (2008) Physiologic mechanisms of sequential products synthesis in 1,3-propanediol fed-batch fermentation by Klebsiella pneumoniae. BiotechnolBioeng 100: 923-932. http://doi.org/10.1002/bit.21830

Zhong J, Karberg M, Lambowitz AM (2003) Targeted and random bacterial gene disruption using a group II intron (targetron) vector containing a retrotransposition-activated selectable marker. Nucleic Acids Res 31: 1656-1664. http://doi.org/10.1093/nar/gkg248 